\title{
Autoritarismo e patrulhamento: sobre a recepção de Armadilha para Lamartine, de Carlos \& Carlos Sussekind pela censura e pela crítica literária nos anos 70
}

\author{
Fabio Bortolazzo Pinto*
}

Resumo: Análise do romance Armadilha para Lamartine, de Carlos \& Carlos Sussekind, a partir de sua recepção no contexto histórico de sua primeira edição (1976).

Palavras-chave: Romance brasileiro; Crítica; Recepção; Anos 70
Abstract: Analysis of the novel Armadilha para Lamartine, by Carlos \& Carlos Sussekind, from its reception within the historical context of its first issue (1976).

Keywords: Brazilian Novel; Criticism; Reception; 70 's

Falar sobre Carlos Sussekind geralmente pressupõe que se apresente autor e obra, visto que ambos seguem semi-desconhecidos do grande público e mesmo do público acadêmico.

O escritor, ilustrador e tradutor Carlos Sussekind nasceu no Rio de Janeiro em 1933. Em grande parte por opção, sua trajetória está ligada a de seu pai, o jurista Carlos Sussekind de Mendonça, autor de diversos livros sobre os mais diversos temas. Polemista, filiado ao partido comunista brasileiro quando este ainda agia na legalidade, Carlos Sussekind de Mendonça, antes de virar personagem pelas mãos do filho, já era um tipo curioso de intelectual cujos interesses iam do esporte ( $O$ sport está deseducando a mocidade brasileira, 1922 - livro saudado publicamente por ninguém menos que Lima Barreto), ao cinema americano (Norma Talmadge e a expressão das emoções na cinematographia americana, 1923), da educação sexual da juventude brasileira (Algumas suggestões à educação sexual dos brasileiros, 1927) à reavaliação de grandes vultos históricos (Quem foi Pedro II - golpeando, de frente, o saudosismo, 1930).

\footnotetext{
* Fabio Bortolazzo Pinto é pós-graduando em Letras, na área de Literatura Brasileira, na Universidade Federal do Rio Grande do Sul.
} 
A grande obra de Carlos Sussekind de Mendonça, porém, é um diário que nos chega através dos livros do filho e a eles está insoluvelmente ligada. O diário de Carlos Sussekind de Mendonça foi escrito durante vinte e cinco anos, cobrindo o período histórico que vai de 1938 a 1963. Carlos Sussekind reescreveu este diário não em sua totalidade, mas alterando trechos, referências, acrescentando coisas aqui e ali. Daí seu texto mais conhecido, Armadilha para Lamartine, de 1976, vir assinado por Carlos \& Carlos Sussekind.

A confusão autoral, instaurada desde o momento em que se fica sabendo das alterações de Carlos filho (imperceptíveis, até por não termos ainda acesso ao diário original) espelha-se no entrelaçamento narrativo das personagens: assim como os dois Carlos são praticamente indistinguíveis como autores, as personagens que os nomeiam no romance, Espártaco e Lamartine, fundem-se na narração de um mesmo episódio: o surto psicótico e a posterior internação de Lamartine em um manicômio. Mais ainda: é no manicômio que Lamartine reescreve por telepatia o diário do pai, num jornalzinho dos internos chamado $O$ Ataque.

O romance é assim dividido em duas partes: a primeira é intitulada "Duas Mensagens do Pavilhão dos Tranqüilos" e se trata de Lamartine, fazendo-se passar por outro interno, Ricardinho, a contar episódios vividos no manicômio. A segunda parte, "Diário da Varandola-gabinete", é o diário de Espártaco telepaticamente reescrito. Há ainda um esclarecimento que antecede as duas partes, quando ficamos sabendo que as "Duas Mensagens" que abrem o livro foram incorporadas posteriormente ao diário.

O labirinto referencial da obra se desdobra para além dela: o surto e a internação são fatos comprováveis da vida de Carlos Sussekind. O diário também existe de fato. Em 2003, Carlos filho encaminhou um projeto ao Instituto Moreira Salles a fim de conseguir um financiamento para a digitalização e transformação do diário de Carlos pai em um banco de dados disponível aos interessados. Os fatos políticos, sociais, econômicos, etc., correspondentes ao período de escrita do diário são nele amplamente comentados e discutidos, daí seu valor histórico, seu caráter de testemunho que justificaria o apoio institucional.

Não foi só em Armadilha para Lamartine que Carlos Sussekind incorporou o texto paterno. De suas cinco obras publicadas (uma novela, três romances e um conto), apenas Ombros Altos, de 1962 e O anti-natal de 1951, de 1994, não fazem referência direta ou contém trechos do diário. 
A reflexão que estamos propondo diz respeito ao significado de Armadilha para Lamartine diante do panorama histórico, cultural, ideológico, que circunda sua primeira edição.

Em 1975, o mercado editorial brasileiro vivia um momento de plenitude. "Conquista de mercado, divulgação de novos autores, interesse pela produção nacional, lucros editoriais maiores" (SUSSEKIND, 2004, p. 35) seriam algumas características deste boom editorial. Como consequiência, os órgãos de censura voltam sua atenção ao tipo de literatura então veiculada.

Durante quase toda a década de 60 e início da década de 70, os departamentos de censura haviam se ocupado predominantemente com o cinema e o jornal, veículos que atingiam mais diretamente o público consumidor de produtos culturais. A pressão do estado porém, havia feito com que em 1975, a indústria do cinema, pelo alto custo envolvido na produção e na importação de filmes entre outras coisas, já praticasse uma espécie de auto censura que, obviamente, limitava seu raio de ação ideológico. O jornal, por sua vez, continuava sob vigilância através de agentes infiltrados e censores mantidos em cada redação. Isso explica o fato de o mercado editorial, por seu caráter ainda de produção artesanal, ter conseguido trabalhar livremente e, de certa forma, "preencher as lacunas de informação dos jornais e dos veículos de massa" (SUSSEKIND, 2004, p.37).

Qual seria, no entanto, o público-alvo deste mercado editorial emergente e que tipo de literatura vinha caindo nas graças deste público?

Digamos que a literatura produzida no período de 64 em diante cumpria uma função compensatória junto à classe média desencantada que, de início, apoiara o regime militar e junto às novas gerações que não haviam presenciado ou sofrido diretamente com o golpe.

O mea culpa da classe média arrependida passaria por um processo de purgação através da leitura ávida dos romances-reportagens, cheios de narrações detalhadas de "sessões de tortura, perseguições policiais e confinamentos" (SUSSEKIND, 2004, p.74). É como se através da "leitura atenta e obsessiva de quaisquer relatos de calvários políticos" (SUSSEKIND, 2004, p. 74), este tipo de leitor pudesse penitenciar, ficcionalmente, suas culpas, por imaginárias que fossem.

Junto às novas gerações, o romance-reportagem e o relato do tipo políticomemorialista viria preencher uma lacuna na formação histórica fragmentária e contraditória de leitores que buscavam através da leitura de versões não oficiais dos fatos relacionados à ditadura, ordenar e reinterpretar a história recente do país. 
Era para estas duas grossas fatias de público que se produziria literatura nos anos 70 e início dos 80. Literatura dividida em dois grandes segmentos, ambos ligados a um tipo de realismo que subordinava o fazer literário à transmissão de uma mensagem políticopanfletária: "de um lado, o naturalismo evidente dos romances-reportagens ou disfarçado das parábolas e narrativas fantásticas; de outro, a 'literatura do eu' dos depoimentos, das memórias, da poesia biográfico-geracional" (SUSSEKIND, 2004, p. 72). Em nenhum dos casos o compromisso com a denúncia de uma visão unilateral dos fatos chega ao questionamento da posição do leitor ou da linguagem que, em muitos destes textos, se mostra conservadora, tradicional e retórica, o que diminui consideravelmente sua eficácia e termina por transformar as atrocidades do regime militar em objeto de consumo, configurando-se como uma face, algo inesperado, da indústria do espetáculo que o regime militar estimulou num primeiro momento.

$\mathrm{O}$ romance de Sussekind, além de não se encaixar em nenhum dos segmentos comercialmente vitoriosos, ainda tinha como agravante o fato de realizar uma sofisticada desmontagem narrativa que, se ainda hoje surpreende pelo grau de elaboração e inventividade, desafiava os parâmetros do tipo de análise crítica praticada nos anos 70 , dentro e fora da academia.

Lembremos, a propósito, que a crítica literária brasileira vivia uma espécie de ocaso: quase sem espaço no jornal, seu veículo por excelência desde o século XIX, ou desempenhando junto a ele apenas as funções de resenhar e polemizar acerca não das obras, mas dos próprios métodos de análise, a crítica enfrentava a difícil adaptação de seus pressupostos ao meio acadêmico. A academia que poderia ter ocupado o vazio da crítica em jornal através da produção universitária em face da "degola promovida pelo Estado e o clima de terror estabelecido, não chegou a cumprir este papel" (LIMA, Luiz Costa apud HOLANDA, 1979, p. 36). A importação semi-indiscriminada de novidades teóricas, prática corrente no meio universitário, traria um outro empecilho ao desenvolvimento da crítica literária: as disputas internas entre os adeptos do estruturalismo, a moda teórica da época, e seus detratores: marxistas mais ou menos ortodoxos, que viam nos pressupostos estruturalistas um caráter arbitrário e anti-histórico, e os inimigos da teoria: intelectuais que agiam como "anjos da guarda, vigias da literatura, defensores de uma crítica sem imperialismos metodológicos, do ensino voltado mais para a criação literária do que para o estudo teórico, e do prazer da leitura antes de tudo" (SUSSEKIND, 2004, p. 56). 
Como resultado deste estado de coisas, a publicação de Armadilha para Lamartine não encontra eco nem entre os inimigos da teoria nem entre os estruturalistas e muito menos entre os críticos de linha marxista.

Um dos pecados mais graves do livro de Sussekind parece ter sido o de passar ileso pela censura o que, ao que tudo indica, bastou para que autor e obra fossem vistos como alienados ou, no mínimo, descompromissados com o questionamento do estado autoritário. As patrulhas ideológicas, termo cunhado por Cacá Diegues em 1978, verdadeiros termômetros do nível de engajamento dos produtores culturais, incapazes de qualquer isenção analítica diante do objeto estético, certamente confirmariam a falta de engajamento de Armadilha para Lamartine.

Um exame atento do livro porém, revela que seu poder de questionamento do autoritarismo, em todos os níveis, vai muito além do que se podia conceber na época de seu surgimento.

No nível temático-temporal, o romance de Sussekind se parece, à primeira vista, com uma bucólica rememoração de fatos históricos e políticos que antecedem o golpe de 64, ainda que cheia de subentendidos e permeada de fina ironia. Sua estrutura narrativa porém, demonstra que o romance está longe de ser apenas isso. Há dois narradores: um pai que através de seu diário pretende dar um sentido único e impor, a qualquer custo, uma determinada ordem à vida familiar cotidiana, e um filho que se sente aprisionado a esta ordem a ponto de reagir através de um surto e reescrever o diário do pai alterando-o de forma a apagar-lhe a autoria. Ora, basta relacionar a figura opressiva do pai à presença sufocante do estado autoritário e a família ao país como um todo para que se veja com clareza o teor corrosivo e crítico desta calculada confusão autoral.

Em uma das poucas críticas relevantes feitas ao livro na época de seu lançamento, Ana Cristina César (1993) perceberia, analisando a forma como se estrutura a narrativa em Armadilha, um caráter de montagem aparentado da narrativa cinematográfica, em que "o narrador se cala de propósito, se recolhe de toda a onipotência, em contraposição a uma literatura de pendor naturalista em que a voz do narrador sabe tudo e conta tudo" (CÉSAR, 1993, p. 68). Esta impressão de ausência de narrador se dá justamente pelo fato de que, tanto o diário do pai quanto o relato do filho no sanatório, onde se faz passar por outro interno, são apresentados como documentos colocados lado a lado para que o leitor os analise e lhes dê significado. Neste caso, o narrador seria apenas responsável pela ordem em que os relatos aparecem no romance. De fato, a única vez em Armadilha para Lamartine em que o narrador intervém diretamente é na introdução, onde apresenta o 
conteúdo do livro de forma aparentemente informativa. O narrador de Sussekind não é, obviamente, tão isento quanto poderia parecer. O próprio autor afirma em entrevista à mesma Ana Cristina César que "a impressão de documento é parte do fingimento literário" (CÉSAR, 1993, p. 67). Não é apenas através da montagem que este narrador influencia a recepção de seu texto. Nas alterações feitas pelo autor no diário do co-autor há, nitidamente, a intenção de deixar claros os limites de uma visão centralizadora e a insanidade do racionalismo que subjaz a esta visão. Ainda que prefira ficar nos bastidores, é o narrador quem dá as cartas, mantendo um controle sutil, mas eficaz da matéria de seu texto. Mesmo assim, fica para o leitor a tarefa de interpretar as duas narrativas que lhe são colocadas e, sendo assim, nada impede que sua aderência a um outro pólo se dê à revelia do processo de apagamento a que nos referimos anteriormente.

Ao se apiedar ou reconhecer no conservadorismo do relato de Espártaco, cuja autoimagem se constrói a partir de um ponto-de-vista de vítima do cotidiano, sempre às voltas com remédios para dormir e gastos exorbitantes, ou se aliar à loucura libertária de Lamartine, denunciador de uma prisão subjetiva que o faz ir parar numa outra prisão, o manicômio, o leitor cai na armadilha que lhe foi cuidadosamente preparada: os dois lados da narrativa são iguais e produzem uma visão dialética do maniqueísmo autoritário produzido pela tentativa de ordenar, controlar, ainda que através de um simples diário, a vida das pessoas à sua volta.

Armadilha para Lamartine é, portanto, um manifesto contra toda forma arbitrária de controle, seja ele exercido de forma explícita ou aparentemente desinteressada. O que o torna um texto relevante não só à época em que foi escrito, publicado e pouco lido, mas, em nossos dias, a todos aqueles que se sintam capazes de viver, via literatura, a experiência transformadora de questionamento dos próprios valores.

\section{Referências}

CÉSAR, Ana Cristina. Escritos no Rio. Rio de Janeiro: UFRJ/ Brasiliense, 1993.

HOLANDA, Heloísa Buarque de. In: GONÇALVES, Marcos Augusto. Anos 70(2) Literatura: 1979-1980. Rio de Janeiro: Europa, 1979.

SUSSEKIND, Carlos \& Carlos. Armadilha para Lamartine. São Paulo: Cia. das Letras, 1998. SÜSSEKIND, Flora. Literatura e vida literária. Belo Horizonte: UFMG, 2004. 